\title{
Article \\ The Role of Grain Boundary Precipitates during Intergranular Fracture in 6xxx Series Aluminium Alloys
}

\author{
Inga G. Ringdalen * $\mathbb{D}$, Ingvild J. T. Jensen, Calin D. Marioara and Jesper Friis \\ SINTEF Industry, P.O. Box 4760 Torgarden, 7465 Trondheim, Norway; ingvildjuliethue.jensen@sintef.no (I.J.T.J.); \\ calin.d.marioara@sintef.no (C.D.M.); jesper.friis@sintef.no (J.F.) \\ * Correspondence: inga.ringdalen@sintef.no
}

Citation: Ringdalen, I.G.; Jensen,

I.J.T.; Marioara, C.D.; Friis, J. The Role of Grain Boundary Precipitates during Intergranular Fracture in 6xxx Series Aluminium Alloys. Metals 2021, 11, 894. https://doi.org/ $10.3390 / \operatorname{met} 11060894$

Academic Editor: JaeHwang Kim

Received: 5 May 2021

Accepted: 25 May 2021

Published: 30 May 2021

Publisher's Note: MDPI stays neutral with regard to jurisdictional claims in published maps and institutional affiliations.

Copyright: (c) 2021 by the authors. Licensee MDPI, Basel, Switzerland. This article is an open access article distributed under the terms and conditions of the Creative Commons Attribution (CC BY) license (https:/ / creativecommons.org/licenses/by/ $4.0 /)$.

\begin{abstract}
During ageing, 6xxx aluminium alloys will develop a microstructure characterised by needle-shaped $\mathrm{Mg} / \mathrm{Si}$-rich precipitates in the bulk, precipitate-free zones along the grain boundaries and larger $\mathrm{Mg} / \mathrm{Si}$-rich precipitates on the grain boundary. Depending on, among other things, the size of the precipitate-free zone, these alloys are prone to intergranular fracture. The role of the grain boundary precipitates during the initiation and propagation of the intergranular fracture is still not fully understood. Transmission Electron Microscopy has been used to characterise the grain boundaries and grain boundary precipitates. The precipitates were found to be of the $\beta^{\prime}$ type surrounded by a layer of U2 structure. The atomic details of relevant interfaces of Al- $\beta^{\prime}$ were characterised for further investigation. Density Functional Theory simulations were performed on the bulk precipitate structures and on the interfaces obtained experimentally. The decohesion energy of these interfaces was calculated and compared to bulk values. In addition, simulated tensile tests were performed in order to find values for the tensile strength $\sigma_{t}$. The dependence of the interfacial energy and tensile strength of $\beta^{\prime}$ grain boundary precipitates were found to depend on the orientation and type of interface in addition to the amount of defects on the interface.
\end{abstract}

Keywords: DFT; TEM; aluminium alloys; grain boundaries; precipitates; ductile fracure

\section{Introduction}

6xxx series aluminium alloys are commonly used in car safety components such as crash boxes and bumper systems. When optimising the heat treatment and work hardening of these materials, it is important to decrease the weight without compromising the strength. The energy-absorbing capabilities of the materials need to be retained through severe plastic deformation without the appearance of cracks. The fracture occurring in these alloys is ductile, and the crack propagation is found to be a combination of transgranular and intergranular fracture, depending on the microstructure [1-3]. The microstructures where intergranular fracture is observed are characterised by precipitate free zones (PFZ) and the occurrence of grain boundary precipitates. PFZs are soft zones in which plastic strain tends to localise and contribute to both the initiation and propagation of ductile fracture [1].

At peak hardness conditions, the main strengthening precipitates in 6xxx series aluminium alloys belong to the $\beta^{\prime \prime}$ phase. The precipitation sequence in Al-Mg-Si alloys from super-saturated solid solution can be summarised as:

$$
\begin{aligned}
S S S S & \rightarrow \text { solute clusters } \rightarrow \text { GP zones }\left(M g_{2+x} A l_{7-x-y} S i_{2+y}\right) \rightarrow \beta^{\prime \prime}\left(M g_{8} S i_{8} A l_{6}\right) \\
& \rightarrow \beta^{\prime}\left(M g_{1.8} S i\right),\left(\mathrm{U} 1, \mathrm{U}_{2}, \mathrm{~B}^{\prime}\right) \rightarrow \beta\left(M g_{2} S i\right), \text { dia-Si }
\end{aligned}
$$

Starting with the Guinier-Preston (GP) zones, all the precipitates have a main coherency direction with the $\mathrm{Al}$ matrix, along $\langle 100\rangle \mathrm{Al}$ directions. As a result, they take on a needle/rod/lath morphology with elongation in these directions. Along the grain boundaries, however, metastable phase precipitation is dependent on whether the grain boundary plane contains a $\langle 100\rangle \mathrm{Al}$ direction from both or one of the adjacent grains. This 
means that coherent metastable precipitation will occur along the grain boundaries with beneficial grain boundary planes. In overaged 6xxx alloys without $\mathrm{Cu}$ and $\mathrm{Zn}$, phases such as $\beta^{\prime}, \mathrm{U} 2$ and $\mathrm{B}^{\prime}$ have been observed, with $\beta^{\prime}$ as the most numerous [4].

The main mechanism for formation of PFZs is diffusion of vacancies and solute atoms towards the grain boundary. This creates a zone depleted of vacancies and solute elements, and thus also of precipitates. The grain boundaries can be potent nucleation sites for precipitates given a beneficial orientation of grain boundary planes for precipitation. Precipitates will be formed at the grain boundaries early during the heat treatment. The growth of these precipitates thereafter drains the region near the grain boundary for solute atoms, making later nucleation of precipitates in the region near the grain boundary impossible.

Ductile fracture in metallic materials is typically assumed to occur through three stages, void nucleation, growth and coalescence [5-7]. Inclusions and constituent particles play an important role in the initiation of ductile fracture as they act as initiation sites for voids, either by particle cracking or particle-matrix decohesion [8,9]. The role of grain boundaries and the precipitate-bulk interfaces is less pronounced but can still be important. They may act as weak zones where the crack can propagate more easily. Strain localisation within the PFZ combined with the larger size of grain boundary precipitates leads to the expectation that the grain boundary precipitates play a more important role than bulk precipitates for ductile fracture in 6xxx aluminium alloys [10,11]. However, the importance of grain boundary precipitates during ductile intergranular fracture is still not fully understood.

The $\beta^{\prime}$ precipitate has been found to be the most common grain boundary precipitate in 6xxx alloys [4]. The details of the $\beta^{\prime}$ precipitate has been the topic of some discussion. Based on TEM studies, the $\beta^{\prime}$ precipitate has been proposed to be rod-shaped and have a hexagonal crystal structure with lattice parameters $a=7.05 \AA$ and $c=4.05 \AA$ [12]. Along the length of the rod, the $\beta^{\prime}$ structure is fully coherent with $\mathrm{Al}\langle 001\rangle$. The symmetry and lattice parameters were confirmed in several studies $[13,14]$, while for some time the exact space group and $\mathrm{Mg}$ :Si atomic ratio remained a subject of confusion [13]. In density functional theory (DFT) calculations with both the local density approximation (LDA) and the generalised gradient approximation (GGA) by Ravi et al. [13], many of the experimentally suggested crystal structures were found to undergo unphysically large geometric relaxations and have positive formation enthalpies compared to Si and $\mathrm{Mg}$ in their separate equilibrium crystal structures. By combining transmission electron diffraction, high-resolution imaging and energy-dispersive X-ray analysis, Vissers et al. [14] were able to establish that the $c$ axis in the $\beta^{\prime}$ structure was actually three times as long as initially thought using electron diffraction (ED). The crystal structure of $\beta^{\prime}$ is hexagonal, space group $P 6_{3} / m$, with unit cell parameters $a=7.15 \AA$ and $c=12.15 \AA$. The composition is $\mathrm{Mg}_{9} \mathrm{Si}_{5}$, with a distribution of $4 \mathrm{Si}$ atoms over six available symmetry sites along the $c$ axis (2/3 occupancy of the $00 z$ Si sites). DFT calculations confirmed that this composition and structure would give a relaxed (equilibrium) $c$ axis coherent with $\operatorname{Al}\langle 001\rangle$. The $\beta^{\prime}$ precipitate has also been observed to sometimes be surrounded by a rearranged zone with U2 structure [15-17].

In this work, we investigate the role of grain boundary precipitates during intergranular fracture in Al-Mg-Si alloys by studying the decohesion energy and tensile strength of the interfaces between $\beta^{\prime}$ grain boundary precipitates and bulk aluminium. Bright field Transmission Electron microscopy (TEM) images are used to characterise grain boundaries and grain boundary precipitates. High-angle annular dark field scanning TEM (HAADF-STEM) is used for in-depth characterisation of the precipitates found on the grain boundaries and to construct representative interface models for first-principle investigations. The decohesion energy of different interfaces in the models is calculated using Density Funtional Theory (DFT). The methodology for ab initio tensile tests established by Janisch et al. [18] is applied to find values for the tensile strength $\sigma_{t}$ of the material. Bulk material, perfect interfaces and interfaces with defects are studied and compared. 


\section{Methods and Models}

\subsection{Experimental Details}

To investigate metastable precipitates that form on grain boundaries with a common $\langle 001\rangle \mathrm{Al}$ direction in the grain boundary plane, an as-extruded 6060 alloy with composition (wt \%) $0.47 \mathrm{Mg}, 0.44 \mathrm{Si}, 0.22 \mathrm{Fe}, 0.02 \mathrm{Mn}, 0.04 \mathrm{Zn}, 0.01 \mathrm{Ti}$ and $0.01 \mathrm{Cr}$ was solution heattreated for $15 \mathrm{~min}$ at $540{ }^{\circ} \mathrm{C}$, water quenched and artificially aged for $5 \mathrm{~h}$ at $185^{\circ} \mathrm{C}$. Grain boundaries and precipitation free zones were imaged in bright field mode with a Philips CM30T TEM (N.V. Philips, Eindhoven, The Netherlands) operated at $150 \mathrm{kV}$. In addition, bulk $\beta^{\prime}$ precipitates were imaged in atomic resolution, Z-contrast high angle annular dark field scanning TEM (HAADF-STEM) mode to determine the crystal structure of this phase's interface with the Al matrix. For this purpose, an ultra-pure alloy with composition (wt \%) $0.63 \mathrm{Mg}, 0.36 \mathrm{Si}$ and $0.22 \mathrm{Ni}$ was artificially aged for $67 \mathrm{~h}$ at $200{ }^{\circ} \mathrm{C}$ to create an overaged microstructure. A double aberration-corrected (image and probe Cs) cold-FEG Jeol ARM$200 \mathrm{~F}$ operated at $200 \mathrm{kV}$ was used for the HAADF-STEM imaging. The probe size was $0.08 \mathrm{~nm}$, the convergence semi-angle was $28 \mathrm{mrad}$ and the inner and outer collection angles were $35 \mathrm{mrad}$ and $150 \mathrm{mrad}$. The imaging was performed along the precipitate needle length parallel to $\langle 001\rangle \mathrm{Al}$ to reveal the projected positions of the atomic columns in cross-section. To improve clarity and remove the grainy noise in the images, an inverse fast fourier transformation (IFFT) was performed to remove all features with separation shorter than $0.15 \mathrm{~nm}$ in the real space by using a circular band pass mask. All TEM specimens were prepared with a TenuPol-5 machine, using a mixture of $\frac{1}{3} \mathrm{HNO}_{3}$ and $\frac{2}{3}$ methanol kept at $-25^{\circ} \mathrm{C}$ and a voltage of $20 \mathrm{~V}$.

\subsection{Computational Details}

Density functional theory (DFT) simulations were performed using the Vienna ab initio simulation package (VASP, VASP Software GmbH, Vienna, Austria) $[19,20]$. The functional used for the calculations was the Perdew-Burke-Ernzerhof (PBE) generalised gradient approximation (GGA) [21]. The criterion for energy convergence was a change of the total energy less than $10^{-6} \mathrm{eV}$. The plane-wave energy cut-off was $400 \mathrm{eV}$, and a gamma sampling of $0.25 k$-points per $\AA$ was used to sample the irreducible Brillouin zone.

The formation enthalpy of the different phases investigated was calculated with

$$
\Delta H=E-n_{A l} E_{A l}-n_{M g} E_{M g}-n_{S i} E_{S i},
$$

where $E$ is the total electronic energy as calculated by VASP and $n_{i}$ and $E_{i}$ are the amount and electronic energy of a single $\mathrm{Mg}$, $\mathrm{Si}$ or $\mathrm{Al}$ solute atom in bulk aluminium, respectively. The energy of a solute atom $X$ is calculated as

$$
E_{X}=E_{A l_{n-1} X}-\frac{n-1}{n} E_{A l_{n}}
$$

where $n$ is the number of atoms in the supercell.

DFT models of two interfaces between $\mathrm{Al}$ and $\beta^{\prime}$ were constructed based on HAADFSTEM images, as described in detail in Section 3.3. The total energy of the models before fracture $\left(E_{\mathrm{tot}}^{\Delta=0}\right)$ was calculated after relaxation of the lattice parameter normal to the interface between $\beta^{\prime}$ and $\mathrm{Al}$, as well as the ion positions. The former restriction was done to preserve bulk lattice parameters for $\mathrm{Al}$ along the interface. To find the total energy of the models after fracture $\left(E_{\text {tot }}^{\Delta \rightarrow \infty}\right)$, selected interfaces were separated by a vacuum layer of $15 \AA$, which was considered long enough to avoid any interactions between the two surfaces. For the models at full separation, only the ion positions were allowed to relax. The break condition for the relaxation loop was set to forces $<0.005 \mathrm{eV} / \AA$, unless otherwise stated. Decohesion energies, also known as the work of separation, were calculated as follows:

$$
E_{\mathrm{decoh}}=\frac{E_{\mathrm{tot}}^{\Delta \rightarrow \infty}-E_{\mathrm{tot}}^{\Delta=0}}{2 A}
$$


where $A$ is the area of the fracture surface.

To simulate tensile tests, a rigid grain shift of the structure were performed [22,23]. An increasingly wider layer of vacuum of width $\Delta$ was inserted, gradually creating two fracture surfaces at selected places in the supercell. Hence, $\Delta=L-L_{0}$ where $L$ is the length of the elongated supercell and $L_{0}$ is the length of the relaxed supercell. In accordance with Janisch et al. [18], we define the binding energy as

$$
E_{b}(\Delta)=-\frac{E_{\text {tot,fixed }}^{\Delta \rightarrow \infty}-E_{\text {tot,fixed }}(\Delta)}{2 A}
$$

where $E_{\text {tot,fixed }}(\Delta)$ is the total energy for separation $\Delta$ calculated without relaxation of the atom positions and lattice parameters and $E_{\text {tot,fixed }}^{\Delta \rightarrow \infty}$ is the total energy for the unrelaxed system with a separation of $15 \AA$.

\subsection{Theoretical Background}

According to Rose et al. [24], the binding energies of metals can be expressed in a universal form:

$$
E_{b}(\Delta)=\left|E_{b}^{e}\right| g(\Delta / l),
$$

where $\left|E_{b}^{e}\right|=-E_{b}(0)$ is the equilibrium binding energy and $l$ a characteristic length. From the second derivative of Equation (6) the characteristic length can be written as

$$
l=\sqrt{\frac{\left|E_{b}^{e}\right| g^{\prime \prime}(0)}{E_{b}^{\prime \prime}(0)}} .
$$

Janisch et al. [18] were able to fit their rigid grain shift tensile tests with

$$
g(a)=-(1+a) e^{-a} .
$$

where $a=\Delta / l$. However, this simple expression is not sufficient to accurately describe the complex rigid fractures studied in this work. We therefore use a more general expression

$$
g(a)=-(1+a+P(a)) e^{-a-Q(a)},
$$

where $P$ and $Q$ are polynomials of order two or larger. Note that this breaks the universal scaling but fulfils our purpose to describe our rigid tensile tests with a simple analytic function and thereby calculate the tensile strength. For $P=Q=0$, Equation (9) reduces to Equation (8).

From Equations (6) and (9), the tensile stress can be calculated as

$$
\sigma=\frac{d E_{b}}{d \Delta}=\frac{\left|E_{b}^{e}\right|}{l} g^{\prime}(a)
$$

The tensile strength $\left(\sigma_{t}\right)$ can be found from the slope at the inflection point:

$$
\sigma_{t}=\max (\sigma)=\frac{\left|E_{b}^{e}\right|}{\left.\lg (a)\right|_{g^{\prime \prime}(a)=0}} .
$$

\section{Results and Discussion}

\subsection{Experimental Observations of Grain Boundary Precipitates}

Figure 1a shows a bright-field TEM image of a low-angle grain boundary in the 6060 alloy. Both grains are oriented with a common [001] Al direction in the grain boundary plane. This creates a dense metastable precipitation along the grain boundary that is imaged in cross-section. Based on the unit cell periodicities, some of these precipitates can be categorised as $\beta^{\prime}, \mathrm{U} 2$ and $\mathrm{B}^{\prime}$ in the enlarged image in Figure 1. This demonstrates that $\beta^{\prime}$ is one type of precipitate that typically forms on such grain boundaries. A bulk 
precipitate in an ultra-pure Al-Mg-Si-Ni alloy providing well-imaged interfaces on all sides of the precipitates was used for construction of the overlay model shown in Figure 2 of the complete atomistic structure of this precipitate. By comparing with the $\beta^{\prime}$ grain boundary precipitates in Figure 1b, we assume that they have a similar crystal structure as the bulk precipitate. One important characteristic of the $\beta^{\prime}$ structure is the presence of a thin interface layer that makes the transition from the core $\beta^{\prime}$ structure to the Al matrix [4]. This layer is mainly of the U2 phase with some disorder. We should note the higher Z-contrast of the corner Si columns, which is in agreement with the higher density of these columns according to the model structure of $\beta^{\prime}$.
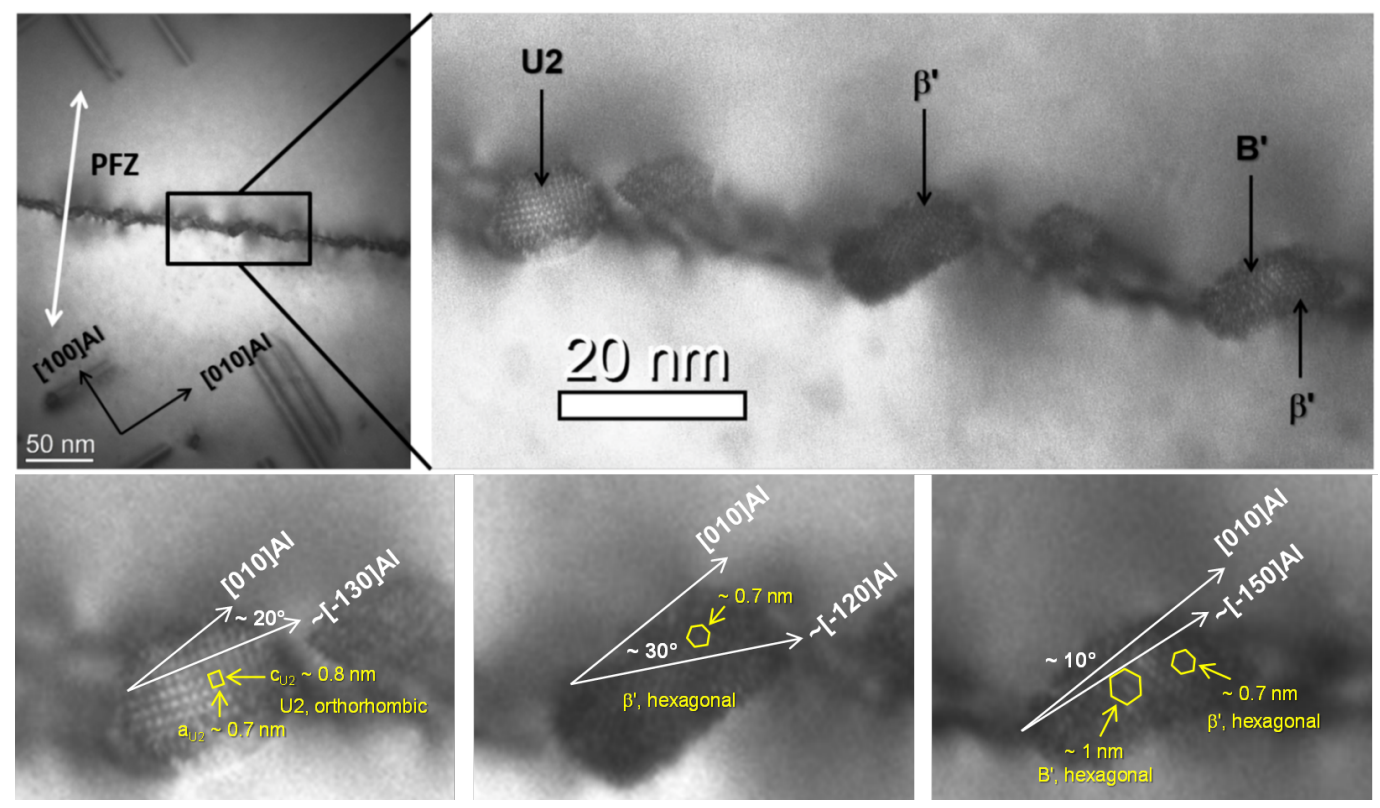

Figure 1. Bright-field TEM image of grain boundary precipitates on a low angle grain boundary in a 6060 aluminium alloy. The unit cell periodicities and angles for the different phases are shown below.

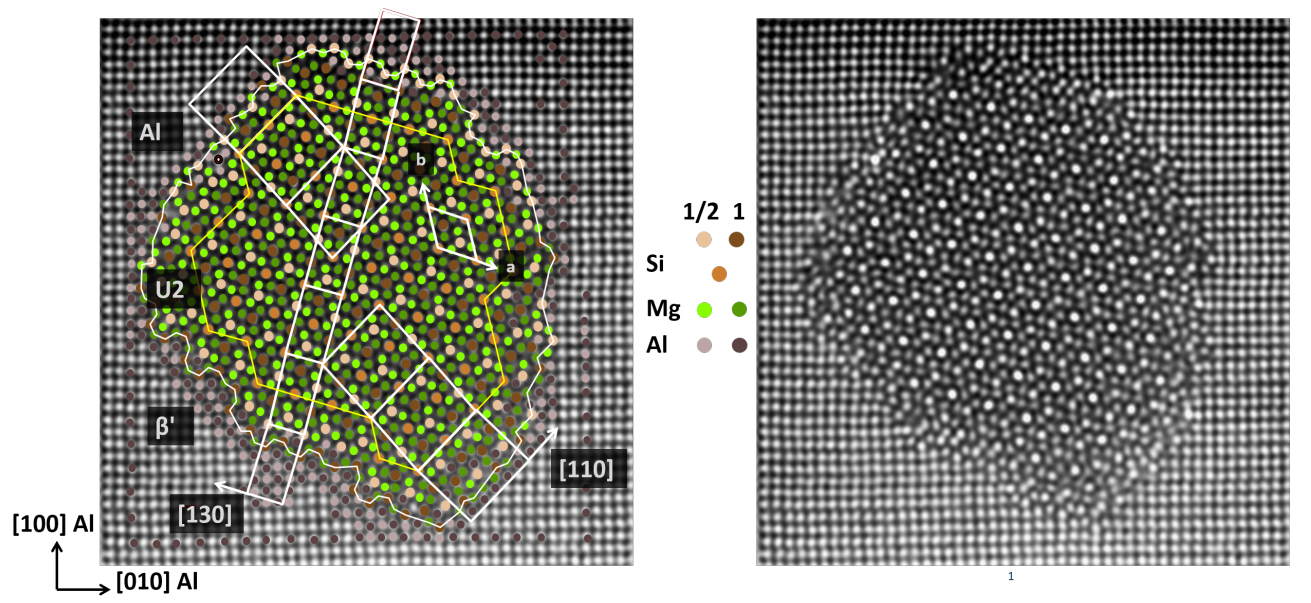

Figure 2. (Colour online). HAADF-STEM image of $\beta^{\prime}$. To the left is the image with an atomic overlay identifying the atomic species, and to the right is the original image. The atomic overlay includes the unit cells used to create the models of the $\mathrm{Al}(130)$ and $\mathrm{Al}(110)$ interfaces. Colouring of the atomic type and height within the aluminium unit cell. The medium-brown Si atom is the column with $2 / 3$ occupancy. The image shows the interface of $\beta^{\prime}$ with the irregular Al matrix, and it is realized through a thin disordered transition layer. The core of the precipitate is delimited with a yellow line and the interface of the transition layer with a white line. 


\subsection{Bulk Properties of $\beta^{\prime}$ and $U 2$}

Basic properties of $\beta^{\prime}$ and $\mathrm{U} 2$ have been investigated to ensure reliable models and to create a foundation for further modelling at higher scales. The unit cell of $\beta^{\prime}$ is illustrated in Figure 3, and U2 is illustrated in Figure 4. Table 1 lists the lattice parameters and formation enthalpies of $\beta^{\prime}$. It includes both the initial unit cell values and the values for full $\mathrm{Si}$ occupancy and with $2 / 3$ occupancy of the $00 z \mathrm{Si}$ sites, as established by Visser et al. [14]. The lattice parameters and formation enthalpies have been investigated both with relaxed unit cell and for a unit cell matching the underlying aluminium lattice (fixed). It was confirmed that the formation enthalpy for $\beta^{\prime}$ with $2 / 3$ occupancy of the $00 z \mathrm{Si}$ sites is significantly lower than with full occupancy. Additionally, it is shown that the relaxed lattice constant in the $c$ direction of bulk $\beta^{\prime}$ with full Si occupancy is too large to be coherent with the aluminium lattice. The relaxed unit cell parameters for $\mathrm{U} 2$ are also listed in Table 1.
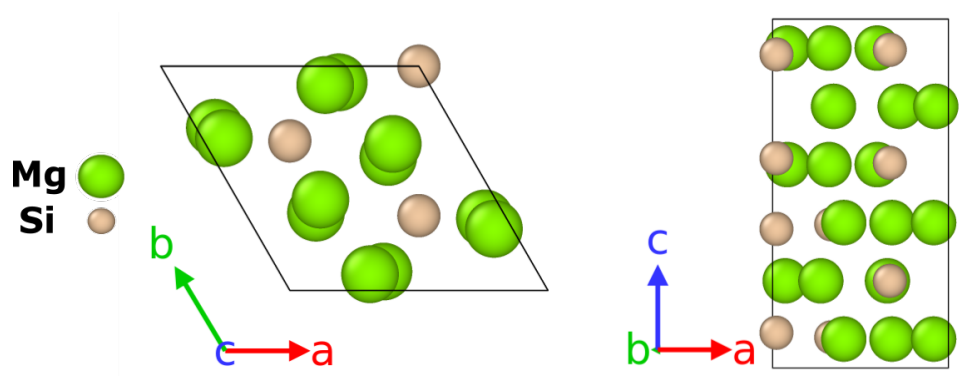

Figure 3. (Colour online). The relaxed unit cell of $\beta^{\prime}$ with $2 / 3 \mathrm{Si}$ occupancy of the $00 z \mathrm{Si}$ sites, as established by Visser et al. [14].

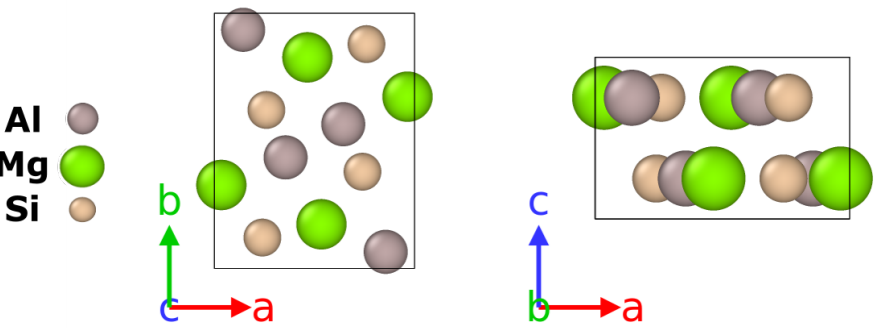

Figure 4. (Color online). The relaxed unit cell of U2 as established by Frøset et al. [16].

Table 1. Unit cell parameters and formation enthalpy of bulk $\beta^{\prime}$ models as given in Equation (2), with full and $2 / 3$ occupancy of the $00 z$ Si sites. "Fixed" unit cell means that the cell parameters were compressed to match the $\mathrm{Al}$ matrix and only the atomic positions were allowed to relax.

\begin{tabular}{cccccc}
\hline Unit Cell & Occ & $\mathbf{a}[\AA \mathbf{A}]$ & $\mathbf{b}[\AA ⿻$ & $\mathbf{c}[\AA ⿻$ & $\begin{array}{c}\Delta \boldsymbol{H} \\
\text { [eV/Atom] }\end{array}$ \\
\hline$\beta^{\prime}$ fixed & $2 / 3$ & 7.13 & 7.13 & 12.10 & -0.337 \\
$\beta^{\prime}$ relaxed & $2 / 3$ & 7.17 & 7.17 & 12.28 & -0.340 \\
$\beta^{\prime}$ fixed & 1 & 7.13 & 7.13 & 12.10 & -0.039 \\
$\beta^{\prime}$ relaxed & 1 & 7.18 & 7.18 & 13.70 & -0.206 \\
\hline U2 relaxed & - & 6.57 & 7.99 & 4.09 & -0.212 \\
U2 fixed & - & 6.37 & 8.20 & 4.03 & -0.207 \\
\hline
\end{tabular}

The unit cells of $\beta^{\prime}$ and $\mathrm{U} 2$ do not match the aluminium unit cell. However, in certain orientation the phases will be close to coherent, and will match with just a small amount of strain. The coherency of $\beta^{\prime}$ with the aluminium matrix in the orientations investigated later is summarised in Table $2 . \beta^{\prime}$ is almost completely coherent in the [110] and [001] aluminium directions, while there is a difference in the [310] direction. 
Table 2. Coherency relations for $\beta^{\prime}, \mathrm{U} 2$ and the aluminium matrix in the directions of the interfaces investigated.

\begin{tabular}{|c|c|c|c|}
\hline Relation & $\mathbf{a}_{A l}[\AA ̊]$ & $\mathbf{a}_{U 2}[\AA]$ & $\mathbf{a}_{\beta^{\prime}}[\AA]$ \\
\hline$[310]_{A l}||[100]_{U 2}||[100]_{\beta^{\prime}}$ & 6.37 & 6.56 & 7.17 \\
\hline $5 \times\left[\frac{1}{2} \frac{\overline{1}}{2} 0\right]_{A l} \| 2 \times[1 \overline{1} 0]_{\beta^{\prime}}$ & 14.25 & - & 14.34 \\
\hline
\end{tabular}

\subsection{Construction of Realistic Interface Models}

DFT supercells were constructed in close agreement with the TEM image in Figure 2, where identification of the atoms and the orientations of the DFT supercells were added as an overlay. The boundary between $\mathrm{Al}$ and $\beta^{\prime}$ is irregular, but two characteristic interfaces can be identified: between $\beta^{\prime}$ and $\mathrm{Al}(130)$ and between $\beta^{\prime}$ and $\mathrm{Al}(110)$. Due to the rotation symmetry of the $\beta^{\prime}$ structure, the structure of the $\beta^{\prime}$ precipitate unit cell used for bulk $\beta^{\prime}$ is the same for both interfaces. At the interface between $\beta^{\prime}$ and $\mathrm{Al}$, a rearranged zone with U2 structure, as earlier observed in the literature [15-17], is present.

The two DFT models, labelled (110) and (130), are shown in Figures 5 and 6. Model (110) consists of a total of 453 atoms, while model (130) consists of 270 atoms. Three different planes were chosen for further investigation. Plane A, which is between the bulk aluminium and the $\mathrm{U} 2$ phase, plane $\mathrm{B}$, which is within the $\mathrm{U} 2$ phase, and plane $\mathrm{C}$, which is within the $\beta^{\prime}$ phase.

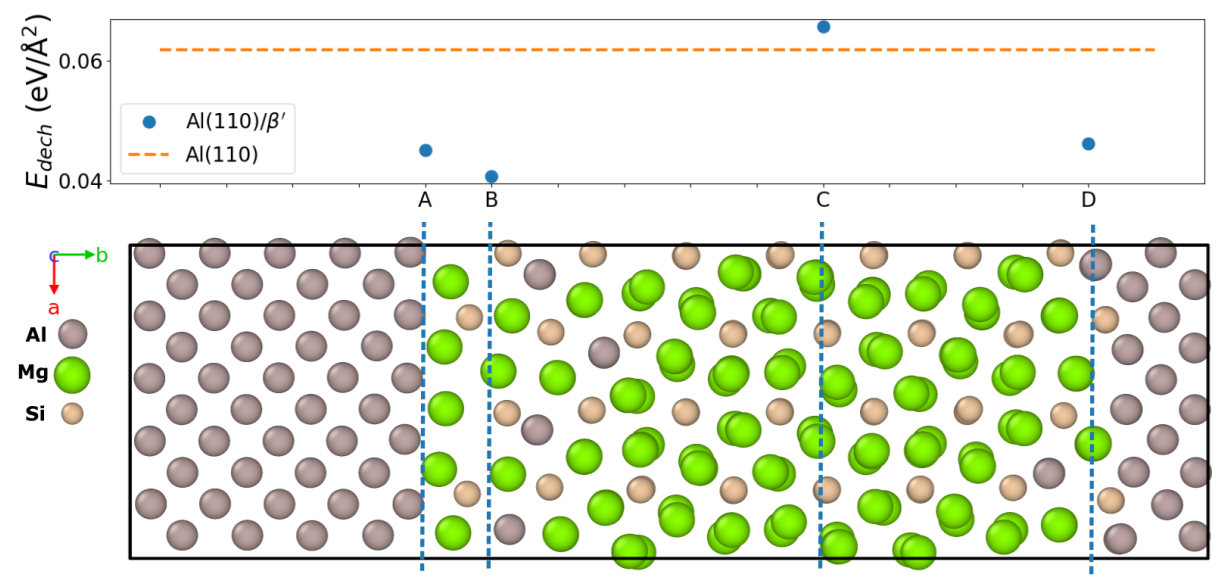

Figure 5. (Color online). Relaxed DFT model of the $\mathrm{Al}(110)$ interface constructed based on the TEM images, with possible decohesion interfaces and corresponding decohesion energies.

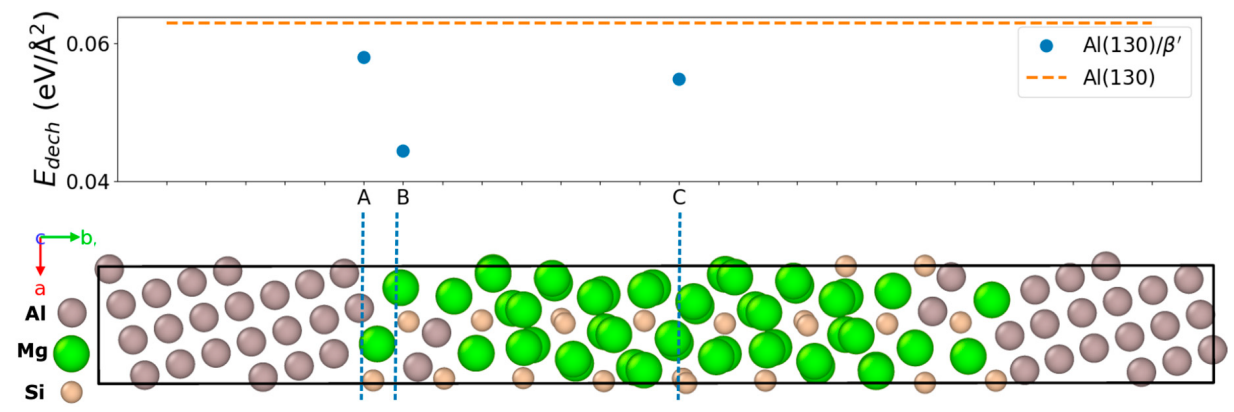

Figure 6. (Color online). Relaxed DFT model of the $\mathrm{Al}(130)$ interface constructed based on the TEM images, with possible decohesion interfaces and corresponding decohesion energies. 


\subsection{Decohesion Energies}

Decohesion energies are calculated for bulk $\mathrm{Al}$, bulk $\mathrm{U} 2$ and bulk $\beta^{\prime}$ materials in addition to the selection of decohesion surfaces described in the illustration of Al- $\beta^{\prime}$ models in Figure 5 and 6 . The decohesion energies are plotted in Figures 5 and 6 and listed in Table 3. The decohesion energies are calculated for both a supercell size in $\mathrm{x}$-direction corresponding to the lattice constant of relaxed $\mathrm{Al}\left(a_{A l}\right)$ and of relaxed $\beta^{\prime}\left(a_{\beta^{\prime}}\right)$.

Bulk $\beta^{\prime}$ has the highest decohesion energy observed in this study. The decohesion plane in bulk $\beta^{\prime}(110)$ and bulk $\beta^{\prime}(130)$ is symmetric, and the decohesion energies of these should therefore be the same, as can be seen for bulk $\beta^{\prime}$ with a supercell size corresponding to relaxed $\beta^{\prime}$ in Table 3. The decohesion energy is found to be decreasing with increasing strain for bulk $\beta^{\prime}$. More strain is needed to match $\beta^{\prime}$ to $\mathrm{Al}$ in the (130) interface than the (110) interface, resulting in a decrease in decohesion energy from $0.072 \mathrm{eV} / \AA^{2}$ to $0.062 \mathrm{eV} / \AA^{2}$. The interface models are also strained in order to match the imposed aluminium lattice constant. The difference in decohesion energy is caused by this strain, which is different for the two different orientations, as shown in Table 2.

The interfaces are found to be weaker than the corresponding lattice plane in pure aluminium. The $\mathrm{U} 2 / \beta^{\prime}$ interface (B) is the weakest interface for both orientations. The (110) orientation has the overall weakest interfaces.

Table 3. Decohesion energy and theoretical strength of the different interfaces investigated with $a$ and $b$ in the $\beta^{\prime}$ unit cell either from relaxed bulk $\mathrm{Al}\left(b_{A l}\right)$ or relaxed bulk $\beta^{\prime}\left(b_{\beta^{\prime}}\right)$.

\begin{tabular}{|c|c|c|c|}
\hline \multirow[t]{2}{*}{ Decohesion Plane } & \multicolumn{2}{|c|}{$\begin{array}{c}\left|E_{b}^{e}\right| \\
{\left[\mathrm{eV} / \AA^{2}\right]}\end{array}$} & \multirow{2}{*}{$\begin{array}{c}\sigma_{t} \\
{[\mathrm{GPa}]}\end{array}$} \\
\hline & $a_{A l}$ & $a_{\beta^{\prime}}$ & \\
\hline $\mathrm{Al}(110)$ & 0.061 & 0.060 & 11.5 \\
\hline $\mathrm{Al}(130)$ & 0.063 & 0.064 & 12.2 \\
\hline U2 (130) & 0.046 & 0.048 & 12.6 \\
\hline$\beta^{\prime}(110)$ & 0.070 & 0.072 & 13.7 \\
\hline$\beta^{\prime}(130)$ & 0.062 & 0.072 & 12.1 \\
\hline (110) $\mathrm{A}-\mathrm{Al} / \mathrm{U} 2$ & 0.045 & 0.043 & 9.4 \\
\hline (110) B-U2 & 0.040 & 0.041 & 9.5 \\
\hline (110) $C-\beta^{\prime}$ & 0.060 & 0.067 & 12.3 \\
\hline (110) D-U2/Al & 0.046 & 0.046 & 11.1 \\
\hline (130) $\mathrm{A}-\mathrm{Al} / \mathrm{U} 2$ & 0.058 & 0.055 & 11.5 \\
\hline (130) B-U2 & 0.044 & 0.048 & 8.5 \\
\hline$(130) C-\beta^{\prime}$ & 0.055 & 0.069 & 10.3 \\
\hline
\end{tabular}

\subsection{Tensile Tests and Tensile Strength}

Virtual tensile tests are performed as described above for all the interfaces defined in Figures 5 and 6. Figure 7 shows the resulting binding energies during the supercell elongation. The fitted curves in Figure 7 were used to calculate the stress-strain curves shown in Figure 8. The tensile strengths of the interfaces found in the virtual tensile tests are listed in Table 3. In general, fracture in bulk $\beta^{\prime}$ and bulk $\mathrm{Al}$ is found to be less favourable than fracture along heterogeneous interfaces. In bulk, the tensile strength, $\sigma_{t}$, ranges from 11.5 to $13.7 \mathrm{GPa}$, while for the interface planes, $\sigma_{t}$ is between 8.5 and $11.5 \mathrm{GPa}$. The tensile strength of the interface planes is all lower than for the bulk precipitates and mostly equal to or lower than bulk aluminium. The interface (110)C is the only one with higher tensile strength than any of the bulk materials. However, (110)C is just slightly strained bulk $\beta^{\prime}$, so this is as expected. 


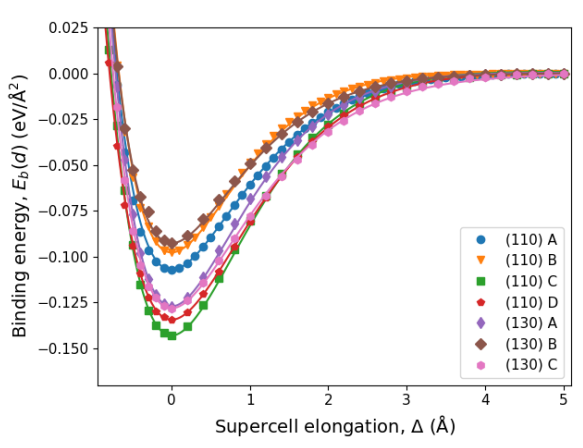

(a) Interfaces

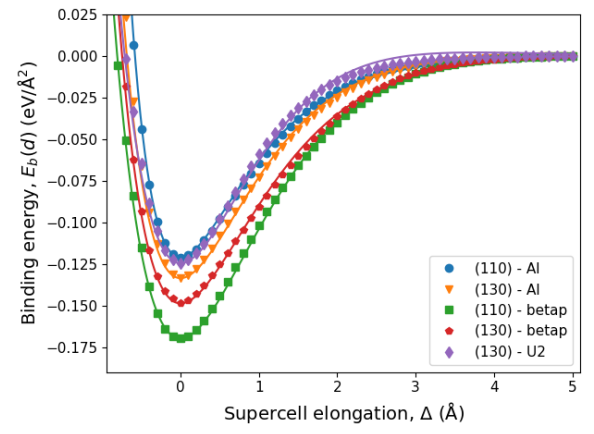

(b) Bulk

Figure 7. (Color online) Fitted binding energies as a function of supercell elongation. The solid lines are fitted using Equation (9). It turned out to be sufficient to only include one term in $P(a)=P_{3} a^{3}$ and non in $Q(a)=0$ to get an excellent fit.

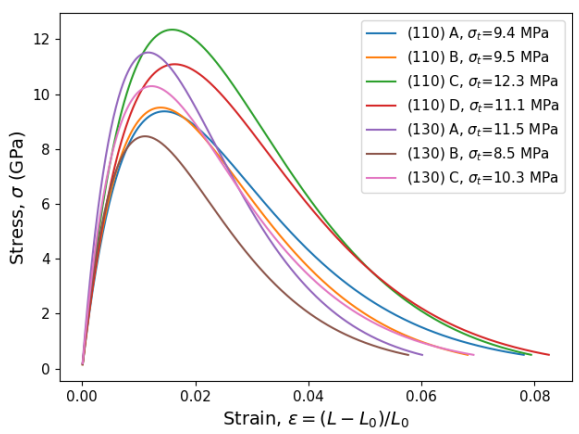

(a) Interfaces

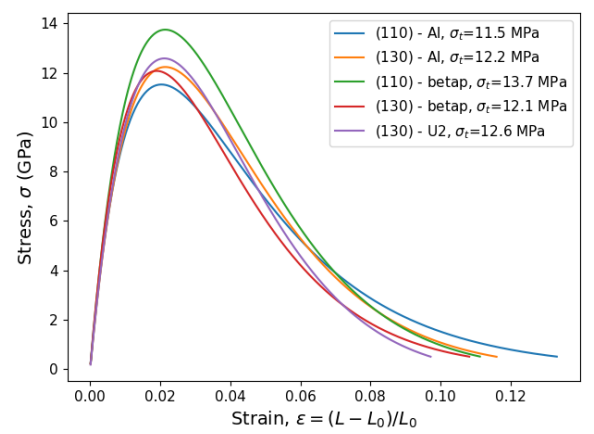

(b) Bulk

Figure 8. (Color online). Calculated theoretical stress-strain curves.

\subsection{Interface Defects}

To indirectly investigate the effect of defects on the decohesion energy and tensile strength, defects are added on the interface by removing columns of atoms, leaving a string of vacancies in the $c$-direction. This will indicate a lower bound of the reduction of the interface strength, as a string of vacancies will remove more mass than will be the case for a dislocation or an interface step. Decohesion plane A (between $\mathrm{Al}$ matrix and U2) was chosen for this investigation, assuming that defects due to dislocation motion are found mainly in the $\mathrm{Al}$ matrix. The resulting lowered decohesion energies for an increasing density of defects are shown in Figure 9. A decrease in decohesion energies with increasing defect density can be observed for both bulk $\mathrm{Al}$ orientations and the (130) interface orientation. For the (110) interface orientation, however, the decohesion energy increases for the first defect (string of one $\mathrm{Al}$ vacancies) before it decreases again for increasing density of vacancies. This is caused by a rearrangement of the interface atoms when adding the defect, resulting in a stronger interface, where some of the $\mathrm{Mg}$ atoms are attached to the $\mathrm{Al}$ interface after decohesion. 


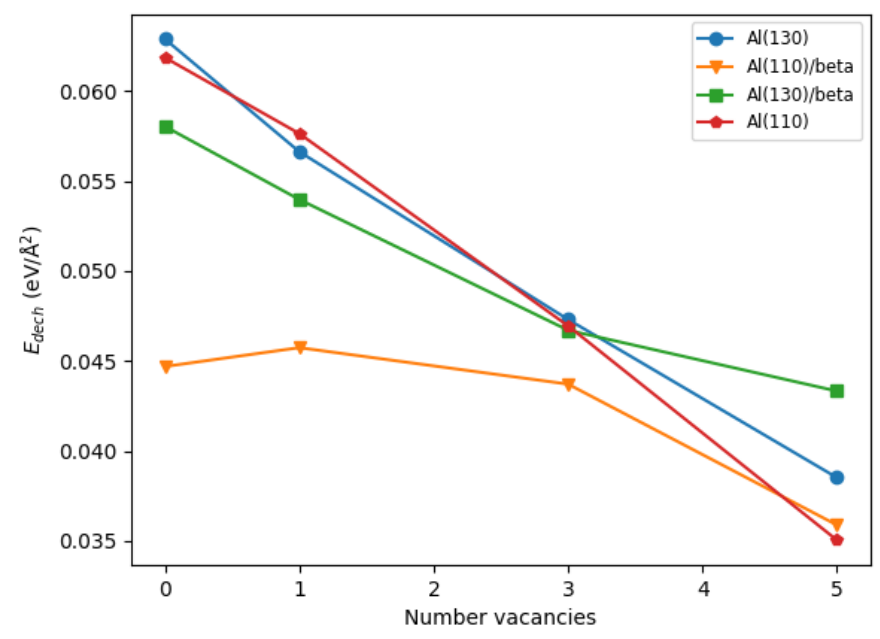

Figure 9. (Colour online) Calculated decohesion energy of the interface models as a function of the number of vacancies added to the decohesion plane.

\section{Conclusions}

Grain boundary precipitates in 6xxx aluminium alloys were studied experimentally using Bright field TEM and High Angle Annular Dark Field Scanning TEM. Interfaces' models were created based on the experimental observations. Density Functional Theory was applied to calculate the decohesion energies and tensile strength of the interfaces. The grain boundary precipitates observed in a 6060 aluminium alloys are mainly of the $\beta^{\prime}$, $\mathrm{B}^{\prime}$ and $\mathrm{U} 2$ type. The $\beta^{\prime}$ precipitates are chosen for further investigations. The $\beta^{\prime}$ precipitates are surrounded by a rearranged zone of U2 structure. The decohesion energies and theoretical strength of grain boundary precipitate interfaces are lower than bulk aluminium and bulk $\beta^{\prime}$ precipitates. The interfaces will weaken additionally by accumulation of defects. The grain boundary precipitates will weaken the grain boundary, as they are a source of inhomogeneities that, together with defects, may be a source for crack formation. The decohesion energies were also found to be influenced by the amount of strain on the interface. The interfaces of $\beta^{\prime}$ precipitates are initially strong; however, they are generally weaker than the matrix. The bulk material of the precipitates are weakened when the material is strained. To fully quantify the weakening of the grain boundary with an increased density of grain boundary precipitates, cohesive zone and crystal plasticity finite element simulations using input from the simulations presented here is needed.

Author Contributions: Conceptualization, I.G.R. and J.F.; methodology, I.G.R., I.J.T.J. and J.F.; software, J.F.; formal analysis, I.G.R., I.J.T.J. and J.F.; experimental investigation, C.D.M.; writing—original draft preparation I.G.R. and I.J.T.J.; writing-review and editing, J.F., C.D.M., I.J.T.J. and I.G.R.; visualization, I.G.R. and I.J.T.J.; project administration, I.G.R.; funding acquisition, I.G.R. All authors have read and agreed to the published version of the manuscript.

Funding: This work was financed by the Research Council of Norway through "Closing the gaps in multiscale materials modelling of precipitation free zones in alloys", FRINATEK project grant number 231762 and through SFI CASA, project grant number 237885. All simulations are carried out on the Sigma2 high performance computer clusters (Grants No. nn9158k and nn9722k).

Institutional Review Board Statement: Not applicable.

Informed Consent Statement: Not applicable.

Data Availability Statement: The raw/processed data required to reproduce these findings cannot be shared at this time due to technical or time limitations.

Acknowledgments: We would like to thank Odd Sture Hopperstad, Afaf Saai and Ida Westermann for fruitful discussions of larger scale experiments and modelling of fracture in aluminium. 
Conflicts of Interest: The authors declare no conflict of interest. The funders had no role in the design of the study; in the collection, analyses, or interpretation of data; in the writing of the manuscript, or in the decision to publish the results.

\section{References}

1. Pedersen, K.O.; Westermann, I.; Furu, T.; Børvik, T.; Hopperstad, O.S. Influence of microstructure on work-hardening and ductile fracture of aluminium alloys. Mater. Des. 2015, 70, 31-44. [CrossRef]

2. Chen, Y.; Pedersen, K.; Clausen, A.; Hopperstad, O. An experimental study on the dynamic fracture of extruded AA6xxx and AA7xxx aluminium alloys. Mater. Sci. Eng. A 2009, 523, 253-262. [CrossRef]

3. Westermann, I.; Pedersen, K.; Børvik, T.; Hopperstad, O. Work-hardening and ductility of artificially aged AA6060 aluminium alloy. Mech. Mater. 2016, 97, 100-117. [CrossRef]

4. Teichmann, K.; Marioara, C.D.; Andersen, S.J.; Marthinsen, K. TEM study of $\beta^{\prime}$ precipitate interaction mechanisms with dislocations and $\beta^{\prime}$ interfaces with the aluminium matrix in Al-Mg-Si alloys. Mater. Charact. 2013, 75, 1-7. [CrossRef]

5. Anderson, T.L. Fracture Mechanics: Fundamentals and Applications; CRC Press: Boca Raton, FL, USA, 2005.

6. Benzerga, A.A.; Leblond, J.B. Ductile fracture by void growth to coalescence. Adv. Appl. Mech. 2010, 44, 169-305.

7. Besson, J. Continuum models of ductile fracture: a review. Int. J. Damage Mech. 2010, 19, 3-52. [CrossRef]

8. Vasudevan, A.K.; Doherty, R. Grain boundary ductile fracture in precipitation hardened aluminum alloys. Acta Metall. 1987, 35, 1193-1219. [CrossRef]

9. Pardoen, T.; Dumont, D.; Deschamps, A.; Brechet, Y. Grain boundary versus transgranular ductile failure. J. Mech. Phys. Solids 2003, 51, 637-665. [CrossRef]

10. Christiansen, E.; Marioara, C.D.; Marthinsen, K.; Hopperstad, O.S.; Holmestad, R. Lattice rotations in precipitate free zones in an Al-Mg-Si alloy. Mater. Charact. 2018, 144, 522-531. [CrossRef]

11. Frodal, B.H.; Christiansen, E.; Myhr, O.R.; Hopperstad, O.S. The role of quench rate on the plastic flow and fracture of three aluminium alloys with different grain structure and texture. Int. J. Eng. Sci. 2020, 150, 103257. [CrossRef]

12. Jacobs, M.H. The structure of the metastable precipitates formed during ageing of an Al-Mg-Si alloy. Phil. Mag. A 1972, 26, 1-13. [CrossRef]

13. Ravi, C.; Wolverton, C. First-principles study of crystal structure and stability of Al-Mg-Si-(Cu) precipitates. Acta Mater. 2004, 52, 4213-4227. [CrossRef]

14. Vissers, R.; van Huis, M.A.; Jansen, J.; Zandbergen, H.W.; Marioara, C.D.; Andersen, S.J. The crystal structure of the $\beta^{\prime}$ phase in Al-Mg-Si alloys. Acta Mater. 2007, 55, 3815-3823. [CrossRef]

15. Matsuda, K.; Sakaguchi, Y.; Miyata, Y.; Uetani, Y.; Sato, T.; Kamio, A.; Ikeno, S. Precipitation sequence of various kinds of metastable phases in Al-1.0mass J. Mater. Sci. 2000, 35, 179-189. [CrossRef]

16. Frøseth, A.G.; Høier, R.; Derlet, P.M.; Andersen, S.J.; Marioara, C.D. Bonding in MgSi and Al-Mg-Si compounds relevant to Al-Mg-Si alloys. Phys. Rev. B 2003, 67, 224106. [CrossRef]

17. Andersen, S.J.; Marioara, C.D.; Frøseth, A.; Vissers, R.; Zandbergen, H.W. Crystal structure of the orthorhombic $\mathrm{U}_{2}-\mathrm{Al}_{4} \mathrm{Mg}_{4} \mathrm{Si}_{4}$ precipitate in the AlMgSi alloy system and its relation to the $\beta^{\prime}$ and $\beta^{\prime \prime}$ phases. Mater. Sci. Eng. A 2005, 390, 127-138. [CrossRef]

18. Janisch, R.; Ahmed, N.; Hartmaier, A. Ab initio tensile tests of Al bulk crystals and grain boundaries: Universality of mechanical behaviour. Phys. Rev. B 2010, 81, 184108. [CrossRef]

19. Kresse, G.; Furthmüller, J. Efficient iterative schemes for ab initio total-energy calculations using a plane-wave basis set. Phys. Rev. B 1996, 54, 11169-11186. [CrossRef]

20. Kresse, G.; Furthmüller, J. Efficiency of ab initio total energy calculations for metals and semiconductors using a plane-wave basis set. Comp. Mater. Sci. 1996, 6, 15-50. [CrossRef]

21. Perdew, J.P.; Wang, Y. Pair-distribution function and its coupling-constant average for the spin-polarized electron gas. Phys. Rev. B 1992, 46, 12947. [CrossRef] [PubMed]

22. Tahir, A.; Janisch, R.; Hartmaier, A. Hydrogen embrittlement of a carbon segregated $\Sigma 5$ (310)[001] symmetrical tilt grain boundary in $\alpha$-Fe. Mater. Sci. Eng. A 2014, 612, 462-467. [CrossRef]

23. Yamaguchi, M. First-principles study on the grain boundary embrittlement of metals by solute segregation: Part I. iron (Fe)-solute (B, C, P, and S) systems. Metall. Mater. Trans. A 2011, 42, 319-329. [CrossRef]

24. Rose, J.H.; Smith, J.R.; Ferrante, J. Universal features of bonding in metals. Phys. Rev. B 1983, 28, 1835-1845. [CrossRef] 